\title{
The Difficult Task of Assessing Psoriatic Arthritis
}

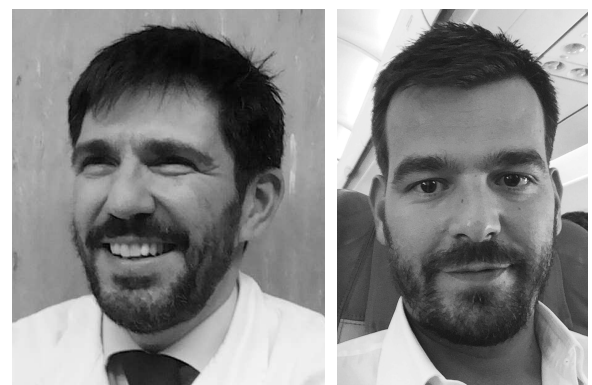

Psoriatic arthritis (PsA) is a systemic inflammatory condition characterized by musculoskeletal involvement associated with cutaneous psoriasis. The PsA clinical picture is generally dominated by peripheral arthritis with or without inflammatory spinal disease, as well as enthesitis and dactylitis ${ }^{1}$. Extraarticular features belonging to the spectrum of spondyloarthropathies are also frequently observed, such as uveitis and gut inflammation ${ }^{2}$. PsA's heterogeneous clinical spectrum is reflected in its complex pathogenesis, where genes and environmental triggers interfere with the innate and acquired immune system ${ }^{3,4,5,6}$. On this basis, it is not surprising that the definition of the key domains and instruments for the evaluation of PsA has been, and remains, challenging.

The present classification of domains is based on the Group for Research and Assessment of Psoriasis and Psoriatic Arthritis (GRAPPA) \& Outcome Measures in Rheumatology (OMERACT) initiative, which proposed a framework for the long list of possible domains ${ }^{7,8}$. Three categories of domains of interest were considered: "inner core," "outer core," and "research agenda." The domains included in the inner core were suggested to be employed in the assessment of patients recruited in all randomized controlled trials (RCT); other relevant domains recommended were listed in the outer core. An additional group of domains requiring further investigations was considered in a third circle as a research agenda. In summary, peripheral joint activity, skin activity, pain, patient global assessment (PGA), physical function, and health related quality of life (HRQOL) were included in the core set. Spinal disease, enthesitis, dactylitis, nail disease, fatigue, physician global assessment, radiography, and acute phase reactants were included in the middle core set. Imaging techniques such as magnetic resonance imaging (MRI) and ultrasound of joints and entheses, tissue analysis, and participation were included in the third set of domains ${ }^{8}$. The extensive research work performed in the last 10 years suggests that it was time to revise the existing PsA core set, providing the opportunity to increase patient involvement in domain and instrument selection. Revision of the core set would also allow to reconsider the priorities in the selection of domains, such as participation (both work and leisure activities) that was not initially included in the core set ${ }^{9,10}$. Domains such as PGA, pain, physical function, and HRQOL still deserve to be included in the core set, with the suggestion arising from patient representatives to add fatigue, which has also been ranked at a high level in the EULAR PsAID study ${ }^{11}$. It has also been suggested to include domains dactylitis and enthesitis (currently in the second circle) in the core set, because of their great clinical importance in PsA and following the development of new assessment instruments.

The increasing importance of patients in these processes and the relevance of the patient perspective in the development and validation of patient-reported outcomes $(\mathrm{PRO})^{12}$ is reflected in the article of Lubrano, et al, published in this issue of The Journal ${ }^{13}$. The authors acknowledge that complex and clinically heterogeneous diseases, such as PsA, are difficult to summarize in all their aspects using PGA instruments or any single instrument ${ }^{14}$; nevertheless, in their study they demonstrated that PGA can also estimate low disease activity status and could be considered a surrogate for outcome measures for the assessment of global disease in patients with PsA during routine clinical practice. Shown to be a rapid and reliable tool, this instrument has demonstrated a strong correlation with minimal disease activity $(\mathrm{MDA})^{15}$, although with limitations as explained by the authors in the Discussion ${ }^{13}$.

In order to update the successful "first edition" of the GRAPPA \& OMERACT core set, consensus must be reached both on which domains to include, as well as on the selection of the most suitable instruments. A framework is clearly needed to embrace the whole spectrum of disease. The proposed new framework includes 4 core "areas": death, life impact (i.e., how disease affects patient life, patient

See Patient's Global Assessment as outcome measure for PsA, page 2332

Personal non-commercial use only. The Journal of Rheumatology Copyright @ 2015 . All rights reserved. 
feelings and function), resource use (all costs caused by the disease), and pathophysiologic manifestations (disease-specific signs and symptoms, biomarkers and potential surrogate outcome measures) ${ }^{16}$. According to the updated OMERACT Filter 2.0. ${ }^{17}$, all assessment core sets (including the PsA core set) should contain at least 1 measurement instrument from the 3 core areas death, life impact, and pathophysiological manifestations; it is also recommended to include 1 measurement from the area resource use ${ }^{18}$.

In conclusion, although to many rheumatologists it may appear logical and practical to embrace all PsA clinical domains in a composite disease activity and responder index summarizing the heterogeneous manifestations of $\mathrm{PsA}^{17}$, this approach remains controversial. In this regard, even patient or physician global scores are not comprehensive or complete enough to encompass assessment of all the clinical domains, such as joints (peripheral and axial), skin, enthesitis, and dactylitis.

For all the above reasons, the need for detailed information on specific domains appears strong and therefore should be obtained by means of several domain-specific instruments, not only in RCT but also in routine clinical practice.

\section{ALBERTO CAULI, $\mathrm{MD}, \mathrm{PhD}$; MATTEO PIGA, MD;}

Rheumatology Unit, Department of Medical Sciences, Policlinico of the University of Cagliari, Monserrato, Italy.

Address correspondence to Dr. A. Cauli, Department of Medical Sciences, Policlinico of the University of Cagliari, ss 554 Monserrato, 09042 Italy; E-mail: cauli@medicina.unica.it

\section{REFERENCES}

1. Wright V, Moll JMH. Psoriatic arthritis. In: Wright V, Moll JMH, editors. Seronegative polyarthritis. Amsterdam: North Holland Publishing Co, 1976:169-223.

2. Gladman DD. Psoriatic arthritis. In: Harris ED, Budd RC, Firestein GS, Genovese MC, Sergent JS, Ruddy S, et al, editors. Kelly's textbook of rheumatology, 7th edition. Philadelphia: W.B. Saunders Co; 2005:1155-64.

3. Mameli A, Cauli A, Taccari E, Scarpa R, Punzi L, Lapadula G, et al. Association of MICA alleles with psoriatic arthritis and its clinical forms. A multicenter Italian study. Clin Exp Rheumatol 2008;26:649-52.

4. Cauli A, Pitzalis C, Yanni G, Hawad M, Panayi GS. CD1 positive antigen presenting cells in psoriatic and rheumatoid arthritis. Rheumatology 2000;6:666-73.
5. Pitzalis C, Cauli A, Pipitone N, Smith C, Barker J, Marchesoni A, et al. Cutaneous lymphocyte antigen-positive $\mathrm{T}$ lymphocytes preferentially migrate to the skin but not to the joint in psoriatic arthritis. Arthritis Rheum 1996;39:137-45.

6. Cauli A, Mathieu A. Th17 and interleukin 23 in the pathogenesis of psoriatic arthritis and spondyloarthritis. J Rheumatol Suppl 2012;89:15-8.

7. Gladman DD, Mease PJ, Healy P, Helliwell PS, Fitzgerald O, Cauli A, et al. Outcome measures in psoriatic arthritis. J Rheumatol 2007;34:1159-66.

8. Gladman DD, Mease PJ, Strand V, Healy P, Helliwell PS, Fitzgerald $\mathrm{O}$, et al. Consensus on a core set of domains for psoriatic arthritis. J Rheumatol 2007;34:1167-70.

9. Tillett W, Adebajo A, Brooke M, Campbell W, Coates LC, FitzGerald $\mathrm{O}$, et al. Patient involvement in outcome measures for psoriatic arthritis. Curr Rheumatol Rep 2014;16:418.

10. de Wit M, Campbell W, FitzGerald O, Gladman DD, Helliwell PS, James $\mathrm{J}$, et al. Patient participation in psoriasis and psoriatic arthritis outcome research: a report from the GRAPPA 2013 annual meeting. J Rheumatol 2014;41:1206-11.

11. Gossec L, de Wit M, Kiltz U, Braun J, Kalyoncu U, Scrivo R, et al. A patient-derived and patient-reported outcome measure for assessing psoriatic arthritis: elaboration and preliminary validation of the Psoriatic Arthritis Impact of Disease (PsAID) questionnaire, a 13-country EULAR initiative. Ann Rheum Dis 2014;73:1012-9.

12. Cauli A, Gladman DD, Mathieu A, Olivieri I, Porru G, Tak PP, et al. GRAPPA 3PPsA Study Group. Patient global assessment in psoriatic arthritis: a multicenter GRAPPA and OMERACT study. J Rheumatol 2011;38:898-903.

13. Lubrano E, Perrotta FM, Parsons WJ, Marchesoni A. Patient's global assessment as an outcome measure for psoriatic arthritis in clinical practice: a surrogate for measuring low disease activity? J Rheumatol 2015;42:2332-8.

14. Coates L, Fransen J, Helliwell PS. Defining disease activity in psoriatic arthritis: a proposed objective target for treatment. Ann Rheum Dis 2010;6948-53.

15. Coates LC, Fitzgerald O, Mease PJ, Gladman DD, Strand V, Goel $\mathrm{N}$, et al. Development of a disease activity and responder index for psoriatic arthritis - report of the psoriatic arthritis module at OMERACT 11. J Rheumatol 2014;41:782-91.

16. Kirwan J, Newman S, Tugwell P, Wells G. Patient perspective on outcomes in rheumatology - a position paper for OMERACT 9. J Rheumatol 2009;36:2067-70.

17. Boers M, Kirwan JR, Wells G, Beaton D, Gossec L, d'Agostino MA, et al. Developing core outcome measurement sets for clinical trials: OMERACT filter 2.0. J Clin Epidemiol 2014;67:745-53.

18. Boers M, Idzerda L, Kirwan JR, Beaton D, Escorpizo R, Boonen A, et al. Toward a generalized framework of core measurement areas in clinical trials: a position paper for OMERACT 11. J Rheumatol 2014;41:978-85.

J Rheumatol 2015;42:2219-20; doi:10.3899/jrheum.151209 